\title{
Aplicando o modelo de proporcionalidade degressiva na representação dos Estados na Câmara dos Deputados
}

\author{
Erinaldo Ferreira Carmo ${ }^{1}$ \\ Enivaldo Carvalho Rocha ${ }^{2}$ \\ Dalson Britto Figueiredo Filho ${ }^{3}$
}

\section{Resumo}

\begin{abstract}
Este artigo investiga a distribuição de cadeiras na Câmara dos Deputados entre os estados brasileiros. A discussão deste tema geralmente toma por base a representação numa regra de proporcionalidade direta entre o número de assentos e o tamanho da população de cada estado. Esta regra apresenta uma distorção na representatividade pelo fato dos estados mais populosos e os menos populosos se afastarem da distribuição proporcional por atingirem o limite máximo e o mínimo, garantidos pela Constituição Federal. Neste caso, os extremos ficam subrepresentados ou sobre-representados. Entretanto, abordamos aqui este assunto sob um outro aspecto, a partir da simulação de aplicação do modelo utilizado na União Européia entre os países membros, com a preocupação de mostrar outra forma de distribuição das cadeiras na Câmara a partir da proporcionalidade degressiva aplicada pelo Parlamento Europeu, o que reduziria o número de parlamentares, mantendo a representação significativa dos estados.
\end{abstract}

Palavras-chave: Representação política. Proporcionalidade degressiva. Sistema eleitoral.

\begin{abstract}
This paper investigates the distribution of seats in the House of Representatives among the states. The discussion of this issue usually is based on the representation of a rule direct proportionality between the states and the size of its population. This rule presents a distorted representation because most populous states and less populous deviate from the proportional distribution by reaching the maximum and the minimum guaranteed by the Federal Constitution. In this case the extremes are underrepresented or overrepresented. However, here we address this issue from another angle, from the application of the simulation model used in the European Union among member countries, with the concern to show another form of distribution of seats in the House from the digressive proportionality applied by the European Parliament, which reduces the number of congressmen and maintains meaningful representation of the countries involved.
\end{abstract}

Keywords: Political representation. Digressive proportionality. Electoral system.

Doutor em Ciência Política e docente do Colégio de Aplicação do Centro de Educação da UFPE.

Doutor em Engenharia de Produção, Mestre em Estatística e Chefe do Departamento de Ciência Política da UFPE.

3 Mestre e doutorando do Programa de Pós-Graduação em Ciência Política da UFPE. 


\section{Introdução}

A desproporcionalidade é um tema comum nos debates sobre a representação dos estados na Câmara dos Deputados. Esta desproporcionalidade na ocupação das cadeiras levanta constantes discussões sobre o espaço ocupado pelos estados e os argumentos comumente se fundam no princípio da representação de cada unidade federativa proporcional ao tamanho de sua população e na distorção oriunda desta desproporcionalidade observada entre representantes e representados.

A atual forma de distribuição das cadeiras permite a sobre-representação dos estados de menor tamanho populacional e a sub-representação dos estados maiores, que têm um número de parlamentares diferente ao que lhe caberia numa proporção direta entre deputados e população estadual. Isto ocorre porque a Constituição Federal de 1988 (Artigo 45, § 1ํ) estabelece o mínimo de oito e o máximo 70 deputados para cada unidade federativa. De acordo com a Constituição, o número de representantes dos estados na Câmara dos Deputados é proporcional à população de cada unidade da Federação, considerando o mínimo e o máximo.

Entretanto, um aspecto deve ser considerado para atender ao que estabelece a Carta Magna: as populações dos estados crescem em ritmos diferentes, daí a necessidade de ajustes periódicos no tamanho das bancadas estaduais, dentro dos limites estabelecidos pela Lei. Neste sentido, as atualizações periódicas do Instituto Brasileiro de Geografia e Estatística, através dos Censos, são imprescindíveis à indicação do tamanho exato da população de cada Unidade Federativa.

O atual formato de distribuição das cadeiras passou a sofrer maiores contestações a partir das distorções geradas com a transformação dos Territórios do Amapá e Roraima em Estados e com a criação de um novo Estado, o Tocantins, durante a Assembléia Nacional Constituinte, cada uma dessas novas unidades federadas com oito deputados, o número mínimo permitido. Ao mesmo tempo, o número máximo permitido passou se 60 para 70, beneficiando São Paulo com mais dez parlamentares.

A partir da distribuição desproporcional dos assentos na Câmara Federal, em efeito cascata, as assembléias legislativas dos estados também reproduzem esta desproporcionalidade de representação. Isto porque as casas legislativas estaduais têm sua composição baseada no tamanho da casa legislativa federal. Por estabelecimento 
constitucional (Artigo 27), as casas legislativas dos estados estão, simultaneamente, ligadas à Câmara Federal no que diz respeito à quantidade de assentos: o número de deputados estaduais está diretamente relacionado ao número de deputados federais que compõe a bancada do estado, numa relação de três deputados estaduais para cada deputado federal, até o limite de 36 deputados estaduais, em correspondência a doze deputados federais. Acima disto a relação é de um deputado estadual para cada deputado federal. A mesma regra se aplica aos deputados distritais.

Consideramos que no modelo político brasileiro o Senado serve de equilíbrio na representação dos estados no Congresso Nacional, entretanto nos atemos aqui à representação populacional neste espaço legislativo, visto que por definição apenas os deputados são os legítimos representantes diretos do povo, enquanto os senadores representam os estados (Constituição Federal, Artigos 45 e 46).

\section{Revendo o caso brasileiro}

No Brasil há uma discussão presente de que existe uma forte assimetria na distribuição das cadeiras na Câmara dos Deputados. Em particular, defende-se que enquanto alguns estados são sobre-representados outros são sub-representados. Assim, o problema da representação desproporcional é apontado como causa de desequilíbrio de forças entre os estados e algo danoso à democracia.

Soares (1973) observa que esta distribuição desproporcional das cadeiras é perniciosa por aumentar o poder político das elites das regiões subdesenvolvidas, "atrasadas, dominadas por líderes locais, latifundistas, proprietários rurais, coronéis", em detrimento do poder das regiões mais desenvolvidas. Nicolau (1997), por sua vez, identifica esta situação como um mal dos sistemas representativos das democracias contemporâneas. Para este, dar pesos diferentes aos votos dos eleitores de cada estado contraria o sentido de que os votos têm valores iguais. Nesta mesma linha, Kinzo (1997) argumenta que, como consequência desta desproporcionalidade representativa, o voto de um eleitor de um estado tem um potencial maior ou menor que o voto de um eleitor de outro estado. Nesta interpretação, os eleitores de Roraima, que representam $0,2 \%$ do eleitorado nacional, elegem $1,5 \%$ das cadeiras da Câmara dos Deputados, enquanto São Paulo, com 22,3\% do eleitorado do país, ocupa $13,6 \%$ das cadeiras. 
Esta visualização da desproporcionalidade direta na distribuição das cadeiras, como mostra a Tabela 1, sugere que São Paulo é o estado mais penalizado por possuir o maior contingente populacional e não ocupar o mesmo espaço de representação na Câmara.

Tabela 1 - Proporcionalidade de representação dos estados

\begin{tabular}{|c|c|c|c|c|c|}
\hline UF & $\begin{array}{l}\text { Eleitorado } \\
\text { (em 2010) }\end{array}$ & $\begin{array}{c}\% \\
\text { (A) }\end{array}$ & $\begin{array}{c}\text { Deputados } \\
\text { Federais }\end{array}$ & $\begin{array}{l}\% \\
\text { (B) }\end{array}$ & $\begin{array}{c}\text { Distorção } \\
\text { (B-A) }\end{array}$ \\
\hline$A C$ & 470.975 & 0,347 & 8 & 1,559 & 1,212 \\
\hline $\mathrm{AL}$ & 2.034 .326 & 1,498 & 9 & 1,754 & 0,256 \\
\hline AM & 2.030 .549 & 1,495 & 8 & 1,559 & 0,064 \\
\hline $\mathrm{AP}$ & 420.799 & 0,31 & 8 & 1,559 & 1,249 \\
\hline $\mathrm{BA}$ & 9.550 .898 & 7,033 & 39 & 7,602 & 0,569 \\
\hline CE & 5.881 .584 & 4,331 & 22 & 4,288 & $-0,043$ \\
\hline $\mathrm{DF}$ & 1.836 .280 & 1,352 & 8 & 1,559 & 0,207 \\
\hline ES & 2.523 .185 & 1,858 & 10 & 1,949 & 0,091 \\
\hline GO & 4.061 .371 & 2,991 & 17 & 3,313 & 0,322 \\
\hline $\mathrm{MA}$ & 4.324 .696 & 3,185 & 18 & 3,508 & 0,323 \\
\hline MG & 14.522 .090 & 10,693 & 53 & 10,331 & $-0,362$ \\
\hline MS & 1.702 .511 & 1,254 & 8 & 1,559 & 0,305 \\
\hline MT & 2.095 .825 & 1,543 & 8 & 1,559 & 0,016 \\
\hline PA & 4.768 .457 & 3,511 & 17 & 3,313 & $-0,198$ \\
\hline PB & 2.740 .079 & 2,018 & 12 & 2,339 & 0,321 \\
\hline $\mathrm{PE}$ & 6.259 .850 & 4,609 & 25 & 4,873 & 0,264 \\
\hline $\mathrm{PI}$ & 2.263 .834 & 1,667 & 10 & 1,949 & 0,282 \\
\hline$P R$ & 7.601 .553 & 5,597 & 30 & 5,847 & 0,25 \\
\hline RJ & 11.589 .763 & 8,534 & 46 & 8,966 & 0,432 \\
\hline $\mathrm{RN}$ & 2.246 .691 & 1,654 & 8 & 1,559 & $-0,095$ \\
\hline RO & 1.079 .327 & 0,795 & 8 & 1,559 & 0,764 \\
\hline $\mathrm{RR}$ & 271.890 & 0,2 & 8 & 1,559 & 1,359 \\
\hline $\mathrm{RS}$ & 8.112 .236 & 5,973 & 31 & 6,042 & 0,069 \\
\hline SC & 4.538 .981 & 3,342 & 16 & 3,118 & $-0,224$ \\
\hline SE & 1.425 .973 & 1,05 & 8 & 1,559 & 0,509 \\
\hline SP & 30.301 .398 & 22,313 & 70 & 13,645 & $-8,668$ \\
\hline TO & 948.920 & 0,699 & 8 & 1,559 & 0,86 \\
\hline EXT. & 200.392 & 0,148 & $-\cdots$ & -- & --- \\
\hline Total & 135.804 .433 & 100 & 513 & 100 & $\ldots$ \\
\hline
\end{tabular}

Com base nesta interpretação e a partir dos dados apresentados, registra-se um fator de desproporcionalidade alarmante, onde o estado de São Paulo afasta-se de todos os outros casos observados, como se vê no Gráfico 1. 


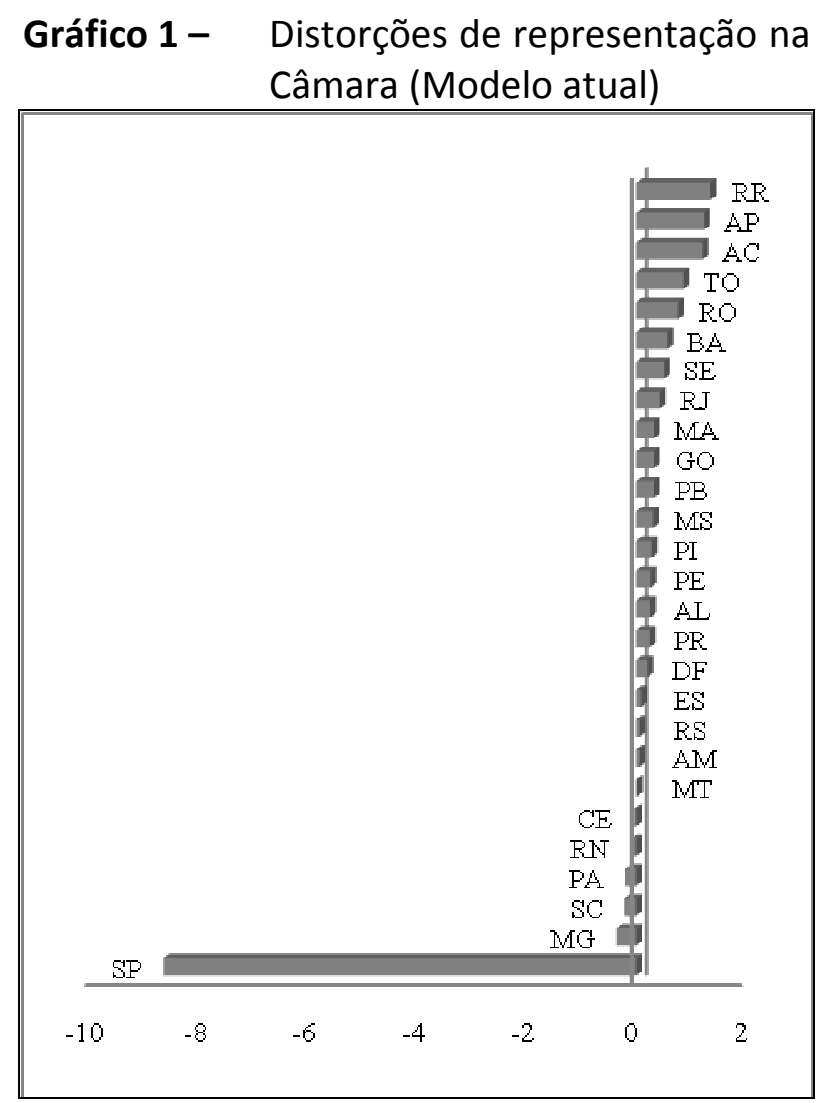

$<=$ Sub-representado / Sobre-representado =>

A bancada de São Paulo aparece, obviamente, como a mais prejudicada por esbarrar no teto máximo permitido pela Constituição Federal (70 deputados), quando o estado deveria ter, numa proporção direta, 111 deputados federais.

Numa outra visão desta representação desproporcional, Santos (1997) percebe que este formato de distribuição das cadeiras não é danoso à democracia, pois permite um equilíbrio das forças entre os Estados pelo fato da sub-representação dos maiores e a sobrerepresentação dos menores compensarem as desvantagens geradas pelo alto custo para obtenção de representação, sendo este um "mecanismo que garante o essencial em um regime representativo, a saber, a não tirania da maioria", isto sem dar à minoria poderes de veto.

Neste sentido, a representação desproporcional também pode ser justificada pela diferença nos custos eleitorais entre candidatos de diferentes estados. No Norte do país a população está bastante dispersa em pequenos grotões longes uns dos outros, o que aumenta o custo da campanha. No Sul e Sudeste a população está distribuída em diversas grandes cidades, o que permite aos candidatos a realização de campanhas em regiões 
distintas. Já nos estados do Nordeste, como observa Ames (2003), a maior parte da população está nas capitais, o que faz com que os candidatos reforcem as campanhas nas Regiões Metropolitanas como complemento às votações recebidas nas bases locais, em municípios interioranos.

Neste atual formato de distribuição das cadeiras, quando aplicada a relação direta de representação entre parlamentares e eleitores, observa-se a discrepância entre os estados maiores e menores da federação. Enquanto em São Paulo a relação é de um deputado federal para cada 432,8 mil eleitores, em Roraima a relação é de um deputado federal para cada 33,9 mil eleitores. Alguns autores, como Soares e Lourenço (2004), fazem uma análise desta desproporcionalidade de representação com base numa relação direta entre parlamentares e eleitores dos estados. Neste tipo de análise é comum encontrar comparações que condenam o formato de representação na democracia brasileira, com alegações de que o voto de um eleitor de Roraima vale até 13 vezes mais que o voto de um eleitor de São Paulo.

Porém, esta discrepância é ainda maior na comparação entre os estados quando observada a representação nas assembléias legislativas. Novamente visualizando os extremos, em São Paulo a relação é de um deputado estadual para cada 322,3 mil eleitores e em Roraima um deputado estadual para cada 11,3 mil eleitores. Enquanto nas assembléias a relação entre parlamentares e eleitores é bastante desuniforme, na Câmara esta relação é mais equilibrada (as exceções ocorrem nos extremos), como visualizamos no Gráfico 2.

Gráfico 2 - Relação de deputado federal por eleitor

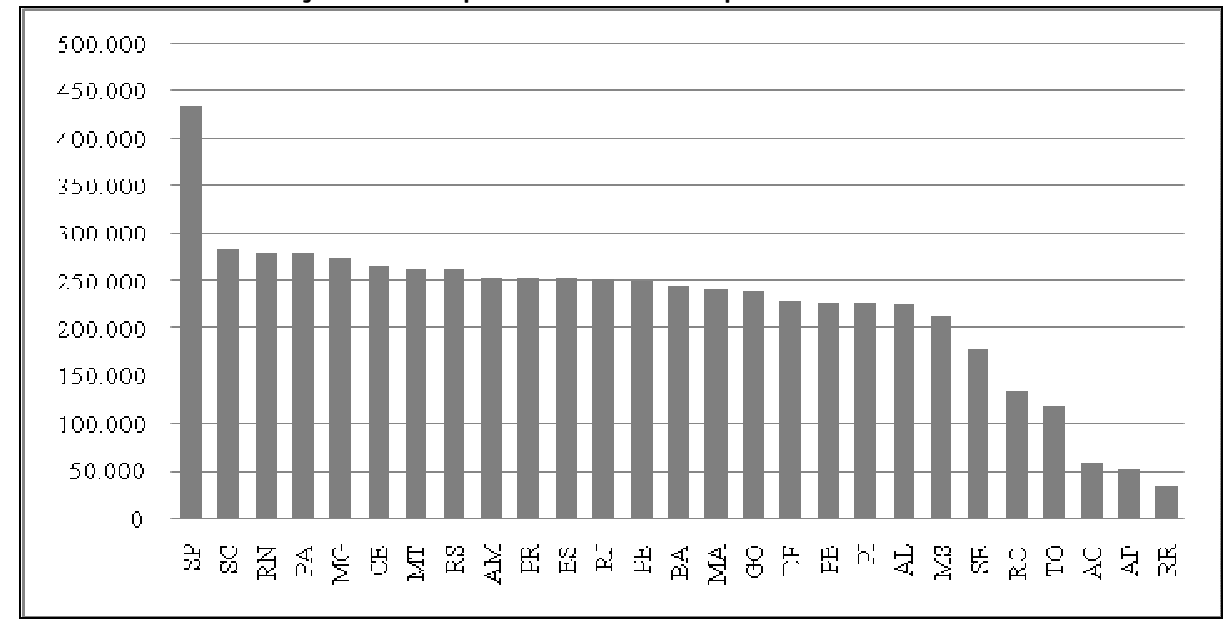

Fonte: TSE 


\section{O princípio consociativo}

A formação de uma federação é apontada por Lijphart (1999) como uma forma de distribuição do poder entre as unidades federativas. Neste caso há uma preocupação com a representatividade dos estados membros e uma inquietação com a possibilidade dos pequenos estados serem sistematicamente derrotados se os votos forem distribuídos de acordo com a população, numa proporção direta. Assim, em vez de adotar o modelo da proporcionalidade estrita de representação, é mais razoável à democracia adotar a representação proporcional degressiva associada ao modelo consociativo, por ser um instrumento de estabilidade política que permite a representação de interesses minoritários, ainda que às vezes contrapostos às vontades da maioria.

Este arranjo federativo reduz o poder da maioria, expressando assim o princípio consociativo de definir a representação não apenas em termos individuais, mas também considerando a representação territorial, cultural e de outras variáveis características dos grupos representados no parlamento. Em uma sociedade com tantas peculiaridades como a nossa, e com estados e regiões tão distintas, há a necessidade de equilibrar as forças políticas no cenário nacional para não submeter os interesses dos estados menores aos interesses dos maiores. Este equilíbrio é vital para a governabilidade dos estados que compõem a federação.

Esta representatividade assegura às unidades federativas e aos grupos territoriais ou regionais um grau de autonomia que credita ao governo local uma força de representação em sua participação no poder central. Ainda evita que os estados com maior número de habitantes decidam reservadamente sobre a formulação das leis e a alocação de recursos. Assim se justifica na federação a redução no grau de igualdade de representação dos indivíduos para poder promover a igualdade de representação das sociedades compreendidas em seus territórios. A vantagem do modelo consociativo adotado por uma federação está na manutenção da representatividade dos diversos grupos territoriais através da garantia de liberdade e poder de participação política das subunidades federativas.

Desta forma, os estados maiores concordam em ceder um pouco de sua representatividade e aceitam a sobre-representação dos estados menores, porém de forma limitada para não inverter a ordem de grandeza, impedindo que estados menores tenham representações acima dos estados maiores. Este formato consociativo de representação foi 
aperfeiçoado pela União Européia com a adoção da proporcionalidade degressiva. Assim, estabeleceu-se uma regra que equilibra a representação dos estados, não eliminando as diferenças, nem igualando a representatividade de todos, mas reduzindo as distâncias que existiriam entre os estados-membros. Isto porque a câmara baixa deve ser uma casa de representação real e equilibrada do povo. Real porque deve conter em si composições que expressem a realidade da sociedade por ela representada; e equilibrada porque deve impedir que grupos maiores sobrepujem as condições de voz e voto dos minoritários.

\section{A proporcionalidade degressiva}

No modelo de proporcionalidade degressiva, o rateio entre a população e o número de vagas no parlamento permite que os deputados de um estado mais povoado representem mais cidadãos do que os deputados de um estado menos povoado, mas também estipula que nenhum estado menos povoado ocupe mais assentos que um estado mais povoado. Assim, há uma consolidação do princípio da solidariedade, através do qual os estados mais povoados aceitam a sub-representação para permitir uma melhor representação dos estados menos povoados, fortalecendo o pacto federativo. É esta proporcionalidade degressiva que aplicamos aqui como uma simulação para observar como ficaria a representatividade dos estados brasileiros na Câmara dos Deputados, bem como nas assembléias legislativas.

No Parlamento Europeu, que nos serve de exemplo para a realização desta experiência, a partir de 2015, de acordo com o Tratado de Lisboa, a Alemanha passará de 99 para 96 cadeiras (o limite máximo), enquanto Malta passará de cinco para seis assentos (o limite mínimo). Caso fosse aplicada a proporcionalidade direta, a Alemanha ficaria com $16,7 \%$ das vagas, mais de 125 cadeiras, e Malta com 0,08\%, apenas uma cadeira.

Fato semelhante ocorrerá no Parlamento do Mercosul, onde está previsto um alargamento para 2015, quando o Brasil terá 75 representantes, a Argentina 43, o Uruguai e o Paraguai com 18 representantes cada. A diferença populacional entre o Brasil (o maior) e o Uruguai (o menor) é mais de 50 vezes favorável ao primeiro. Entretanto, este terá apenas 4,1 vezes mais o número de representantes. Não fosse esta forma, e sim uma proporcionalidade direta, o Brasil teria $79 \%$ das cadeiras, enquanto o Uruguai ocuparia apenas $1,4 \%$ das vagas. Estas discrepâncias poderiam impedir a relação dialógica entre os 
maiores e os menores estados, dificultando o processo de argumentação e negociação, tão relevantes para a manutenção de um espaço democrático, como precisa ser o parlamento. Por isso se justifica até um certo grau de desproporcionalidade na representação.

O exercício de aplicação do modelo europeu ao caso brasileiro reduziu o número de parlamentares, mantendo a significativa representação dos estados. São 84 cadeiras a menos na Câmara, o que implica na redução simultânea no número de deputados estaduais/distritais, que passariam dos atuais 1.059 para 1.015. Nesta simulação é possível admitir uma redistribuição das cadeiras restantes, ajustando o número de representantes por estado, dentro da proporcionalidade degressiva e mantendo o máximo de 513 cadeiras, como determina a Lei Complementar 78/93. Mas neste caso os beneficiados deveriam ser os estados sub-representados.

Este modelo de proporcionalidade degressiva, adotado para a representação dos estados-membros do Parlamento Europeu, sugere a correção dos sub e dos sobrerepresentados, equilibrando as forças e, principalmente, reduzindo os extremos. $\mathrm{Na}$ adaptação deste modelo ao caso brasileiro a distribuição das cadeiras na Câmara dos Deputados e nas casas legislativas estaduais amenizaria as discrepâncias, e ainda preservaria as maiores bancadas aos maiores estados, sem prejuízo à representatividade dos estados menores.

\section{Aplicando o modelo degressivo}

O modelo de proporcionalidade degressiva, elaborado por Taagepera e Hosli (2006), permite a distribuição equilibrada das cadeiras entre os estados através de uma fórmula que amortece as grandes distorções:

$$
S_{i}=\left(S P_{i}^{n}\right) /\left(\sum P_{j}^{n}\right)
$$

Sendo:

$n=[1 / \log (N)-1 / \log (S)] /[1 / \log (N)-1 / \log (P)]$

Onde:

$\mathrm{S}_{\mathrm{i}}=$ número de cadeiras por estado

$\mathrm{P}_{\mathrm{i}}=$ população do estado

$\mathrm{P}=$ população total

$\mathrm{S}=$ total de cadeiras

$\mathrm{N}=$ número de estados 
A simulação da aplicação deste modelo ao caso brasileiro, com a representação dos estados a partir da proporcionalidade degressiva, mostra que este formato de representação dos estados reduziria o número de parlamentares, mantendo a significativa representação das unidades federativas e suas respectivas populações, como se apresenta na Tabela 2.

Tabela 2 - Representação dos Estados na Câmara dos Deputados

\begin{tabular}{|c|c|c|c|c|c|}
\hline \multirow[b]{2}{*}{ UF } & \multirow{2}{*}{$\begin{array}{l}\text { População } \\
\text { (em 2010) }\end{array}$} & \multicolumn{2}{|c|}{$\begin{array}{c}\text { Modelo } \\
\text { atual }\end{array}$} & \multicolumn{2}{|c|}{$\begin{array}{c}\text { Modelo } \\
\text { degressivo }\end{array}$} \\
\hline & & Cadeiras & $\%$ & Cadeiras & $\%$ \\
\hline$A C$ & 732.793 & 8 & 1,56 & 8 & 1,86 \\
\hline $\mathrm{AL}$ & 3.120 .922 & 9 & 1,75 & 11 & 2,56 \\
\hline AM & 3.480 .937 & 8 & 1,56 & 12 & 2,80 \\
\hline AP & 668.689 & 8 & 1,56 & 8 & 1,86 \\
\hline $\mathrm{BA}$ & 14.021 .432 & 39 & 7,60 & 25 & 5,83 \\
\hline CE & 8.448 .055 & 22 & 4,29 & 19 & 4,43 \\
\hline DF & 2.562 .963 & 8 & 1,56 & 10 & 2,33 \\
\hline ES & 3.512 .672 & 10 & 1,95 & 12 & 2,80 \\
\hline GO & 6.004 .045 & 17 & 3,31 & 16 & 3,73 \\
\hline MA & 6.569 .683 & 18 & 3,51 & 17 & 3,96 \\
\hline MG & 19.595.309 & 53 & 10,33 & 31 & 7,23 \\
\hline MS & 2.449 .341 & 8 & 1,56 & 10 & 2,33 \\
\hline MT & 3.033 .991 & 8 & 1,56 & 11 & 2,56 \\
\hline PA & 7.588 .078 & 17 & 3,31 & 18 & 4,20 \\
\hline PB & 3.766 .834 & 12 & 2,34 & 12 & 2,80 \\
\hline $\mathrm{PE}$ & 8.796 .032 & 25 & 4,87 & 20 & 4,66 \\
\hline $\mathrm{PI}$ & 3.119 .015 & 10 & 1,95 & 11 & 2,56 \\
\hline PR & 10.439 .601 & 30 & 5,85 & 22 & 5,13 \\
\hline RJ & 15.993 .583 & 46 & 8,97 & 27 & 6,29 \\
\hline RN & 3.168 .133 & 8 & 1,56 & 11 & 2,56 \\
\hline RO & 1.560 .501 & 8 & 1,56 & 8 & 1,86 \\
\hline $\mathrm{RR}$ & 451.227 & 8 & 1,56 & 8 & 1,86 \\
\hline RS & 10.695 .532 & 31 & 6,04 & 22 & 5,13 \\
\hline SC & 6.249 .682 & 16 & 3,12 & 16 & 3,73 \\
\hline SE & 2.068 .031 & 8 & 1,56 & 9 & 2,10 \\
\hline SP & 41.252 .160 & 70 & 13,65 & 47 & 10,96 \\
\hline TO & 1.383 .453 & 8 & 1,56 & 8 & 1,86 \\
\hline Total & 190.732 .694 & 513 & 100 & 429 & 100 \\
\hline
\end{tabular}

Fontes: TSE; IBGE. 
Com o emprego do modelo degressivo de proporcionalidade, que permite uma distribuição mais ajustada dos assentos, adequada ao princípio consociativo de federação, nota-se que alguns estados que são classificados como sobre-representados no modelo atual de distribuição, por serem beneficiados pela garantia constitucional de oito representantes ( $A C, A P, R O, R R$ e $T O$ ), na verdade ocupam uma quantidade correta de assentos, como apresenta o Gráfico 3. Para esta mesma distribuição degressiva, observa-se que os estados de São Paulo, Minas Gerais, Rio de Janeiro e Bahia, dentre outros, estão sobre-representados na Câmara, enquanto os estados do Amazonas, Rio Grande do Norte e Mato Grosso, dentre outros, estão sub-representados. Estas diferenças são facilmente percebíveis na comparação entre os Gráficos 1 e 3, entre o modelo real (atual) e o degressivo (simulado), respectivamente.

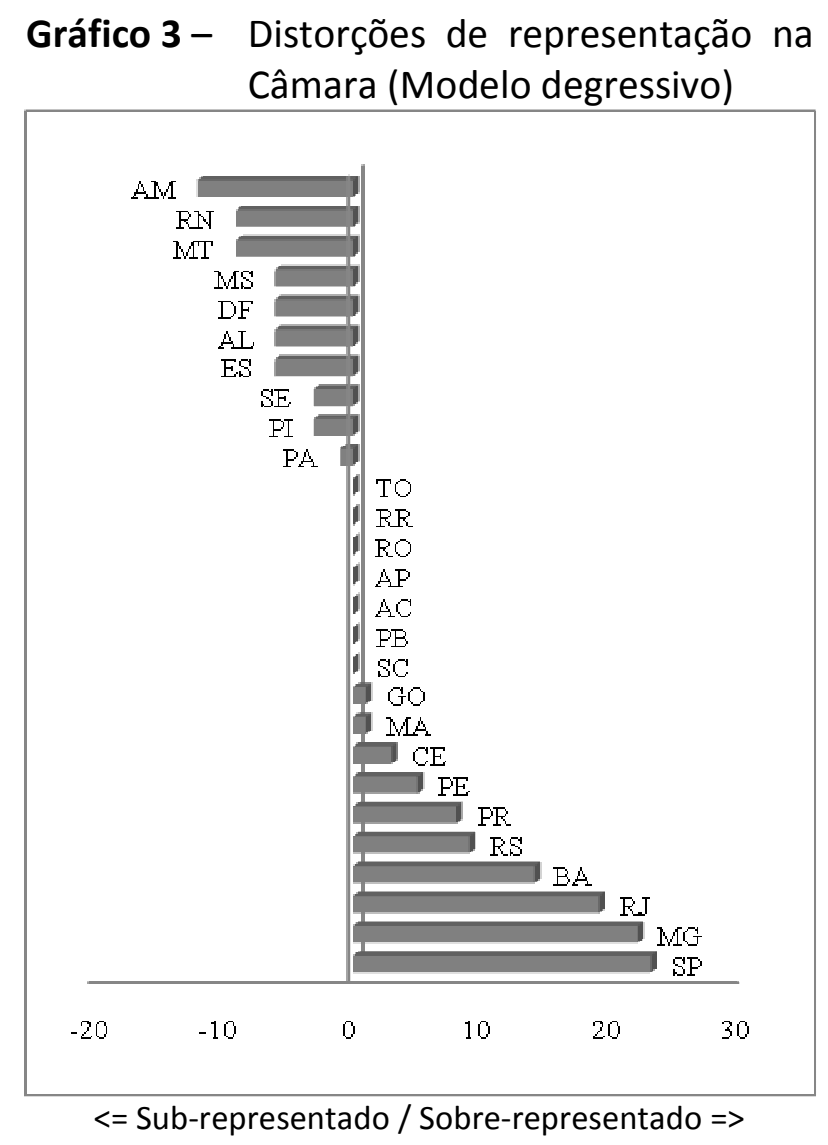

Neste sentido, na comparação desta regra aqui apresentada com o atual quantitativo de representantes de cada estado brasileiro na Câmara, percebemos que o estado de São Paulo possui uma representação superior ao número que lhe caberia dentro 
de uma proporcionalidade degressiva, contrariando os argumentos comuns de que o maior estado do país estaria prejudicado em sua representação na Federação.

$\mathrm{Na}$ aplicação do modelo de representação degressiva à distribuição das cadeiras na Câmara dos Deputados teríamos o formato representado no Gráfico 4, mantendo a maior quantidade de cadeiras às unidades federativas de maior população. A mesma regra se aplicaria aos parlamentos dos estados e do Distrito Federal.

Gráfico 4

Distribuição das cadeiras por estado

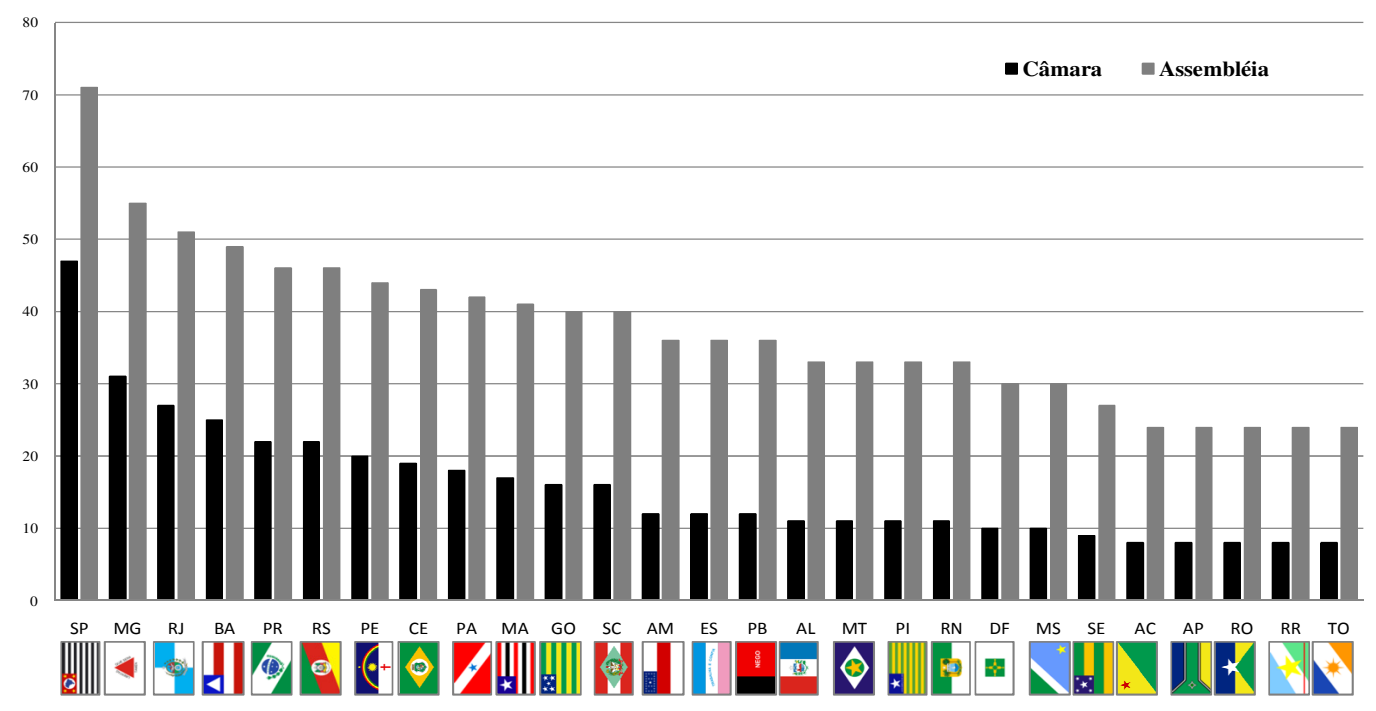

\section{Considerações finais}

A argumentação de sub-representação dos grandes estados e sobre-representação dos pequenos pode ser contestada se comparada ao modelo aqui apresentado. Quando aplicamos ao caso brasileiro o modelo de representação por proporcionalidade degressiva, desenvolvido por Taagepera e Hosli (2006) para a distribuição de cadeiras no Parlamento, percebemos que continua havendo uma desproporcionalidade de representação, entretanto a posição dos estados é alterada. Como exemplo, São Paulo deixa de ser observado como sub-representado, passando a ser enquadrado como um estado de sobre-representação.

Neste formato, a bancada de São Paulo permanece sendo a maior da Federação, mas seu distanciamento do estado de Alagoas, por exemplo, cai de 61 deputados, no atual 202

Revista de Direito PúBlico, Londrina, V. 7, N. 3, P. 191-204, SET./DEZ. 2012. 
formato, para 36, no modelo degressivo. É que a proposta degressiva respeita a regra de distribuição proporcional das cadeiras, entretanto a discrepância é drasticamente reduzida.

Atualmente, no cenário nacional, os menores estados ocupam 1,5\% das cadeiras, cada um, enquanto o maior, São Paulo, ocupa 13,6\% dos assentos. Através da proporcionalidade degressiva os menores ocupariam 1,8\% das cadeiras, cada um, já São Paulo ficaria com 10,9\%. Minas Gerais, o segundo maior colégio eleitoral do país, passaria de 10,3\% para 7,2\% em ocupação das vagas na Câmara. Isto não prejudicaria a democracia, ao contrário, equilibraria a representatividade de toda a população nacional, fortalecendo o diálogo e impedindo que prevaleçam os interesses dos maiores. O diálogo equilibrado entre os estados favorece o federalismo e o princípio consociativo.

A simulação aqui apresentada mostra, ainda, que a aplicação do modelo de representação degressiva ao caso brasileiro reduziria o número de parlamentares, mantendo a significativa representação dos estados. Além disso, como a fórmula aplicada amortece as grandes distorções, os dados sugerem que São Paulo, Minas Gerais e Rio de Janeiro estão, na verdade, sobre-representados, enquanto Amazonas, Rio Grande do Norte e Mato Grosso deveriam ter mais assentos na Câmara dos Deputados.

Com a distribuição das cadeiras baseada na proporcionalidade degressiva mantémse o equilíbrio de forças entre os estados, sem alterar a ordem de grandeza destes, preservando aos maiores conglomerados populacionais uma reserva maior de vagas, mas fortalecendo o equilíbrio de participação entre as unidades federativas. Neste caso, as discrepâncias são reduzidas a níveis comedidos, com a população de cada estado sendo representada significativamente na Câmara e nas respectivas casas legislativas estaduais.

\section{Referências}

AMES, B. Os Entraves da Democracia no Brasil. Rio de Janeiro: FGV, 2003.

BRASIL. Constituição Federal. Congresso Nacional: Brasília, 1988.

KINZO, M. D. Governabilidade, Estrutura Institucional e Processo Decisório no Brasil. Parcerias Estratégicas, v. 1, n. 3, 1997.

LIJPHART, A. Patterns of democracy: government forms and performance in thirty-six countries. New Haven, Yale University Press, 1999. 
NICOLAU, J. As Distorções na representação dos Estados na Câmara dos Deputados Brasileira. Dados, v. 40, n. 3, 1997.

SANTOS, W. G. Representação, Proporcionalidades e Democracia. Revista Estudos Eleitorais TSE, v. 1, n. 1, 1997.

SOARES, G. Desigualdades Eleitorais no Brasil. Revista Ciência Política, n. 7, 1973.

SOARES, M. M.; LOURENÇO, L. C. A representação política dos estados na federação brasileira. RBCS, v. 19, n. 56, 2004.

TAAGEPERA, R; HOSLI, M. O. National Representation in International Organizations: the seat allocation model implicit in the European Union Council and Parliament. Political Studies, v. 54, 2006.

Artigo recebido em 20/10/2012 e aprovado para publicação em 30/11/2012. 